\title{
Smart Residential Buildings as Learning Agent Organizations in the Internet of Things
}

\author{
Markus Schatten
}

University of Zagreb, Faculty of Organization and Informatics

\section{Abstract}

Background: Smart buildings are one of the major application areas of technologies bound to embedded systems and the Internet of things. Such systems have to be adaptable and flexible in order to provide better services to its residents. Modelling such systems is an open research question. Herein, the question is approached using an organizational modelling methodology bound to the principles of the learning organization. Objectives: Providing a higher level of abstraction for understanding, developing and maintaining smart residential buildings in a more human understandable form. Methods/Approach: Organization theory provides us with the necessary concepts and methodology to approach complex organizational systems. Results: A set of principles for building learning agent organizations, a formalization of learning processes for agents, a framework for modelling knowledge transfer between agents and the environment, and a tailored organizational structure for smart residential buildings based on Nonaka's hypertext organizational form. Conclusions: Organization theory is a promising field of research when dealing with complex engineering systems.

Keywords: smart residential buildings, organizational design, internet of things, learning organization, embedded systems, multi-agent systems

JEL main category: Mathematical and Quantitative Methods

JEL classification: C0, C61, C88

Paper type: Research article

Received: 31, December, 2012

Accepted: 20, January, 2014

Citation: Schatten, M. (2014), "Smart Residential Buildings as Learning Agent Organizations in the Internet of Things", Business Systems Research, Vol. 5, No. 1, pp. 34-46.

DOI: 10.2478/bsrj-2014-0003

Acknowledgments: The work has been partly supported by the European Commission under the project FP7-SME-2011-286583 'MODUS' and partly by the project Organizational Design of Multi-agent systems for the Internet of Things (Organizacijsko oblikovanje višeagentnih sustava $u$ Internetu stvari) funded by the University of Zagreb, Croatia.

\section{Introduction}

The Internet of Things (IOT) represents "a variety of things or objects (...) which, through unique addressing schemes, are able to interact with each other and 
cooperate with their neighbours to reach common goals" (Atzori, lera, Morabito, 2010). These things include numerous different (often embedded) devices including but not limited to sensors of various kinds, actuators, mobile devices, TV sets, vehicle computers; but also non-ICT appliances (dishwashers, microwave ovens, refrigerators), electrical energy sources and building components (Hu et al., 2011). Some of the key application areas of loT are smart cities (Vlacheas et al., 2013), smart power grids (Yun, Yuxin, 2010), smart health (Bui, Zorzi, 2011), smart transport (Vermesan et al., 2011), as well as smart buildings (Welbourne et al., 2009) which includes smart living solutions (Dohr et al., 2010).

In the following research we will concentrate on the particular aspect of smart residential buildings which can be various building types including but not limited to apartment blocks, asylums, condominiums, dormitories, duplex, numerous house types etc. The important commonality between these types of buildings is that they are habitats to people and thus must be able to adjust to their needs and behaviour in order to provide a pleasant living experience.

Smart things in IoT can and should be analyzed as agents within multi-agent systems (MAS) and this is the approach taken herein. Various embedded systems in such devices often show (at least in a physical sense) a certain degree of autonomy (Pejić Bach, Stepanić, Strugar, 2012), are context (environment) aware, in most cases benevolent, rational, adaptable (able to learn), social (aware of other things), reactive and proactive - all of which are characteristics of agents as described in (Wooldridge, 2009).

MAS are not simply sets of self-interested individual agents. Agents within MAS have to be organized in order to achieve certain objectives. There have been numerous studies that applied organization theory approaches to the design of agent organizations including but not limited to (Argente, Julian, Botti, 2006; Blanzieri et al., 2001a, 2001b, 2004; Desai, Chopra, Singh, 2009; Ferber, Gutknecht, Michel, 2004; Filipe, Fred, 2007; Filipe, 2004; Fischer, Schillo, Siekmann, 2003; Garcia, Argente, Giret, 2008; Horling, Lesser, 2005; Kolp, Giorgini, Mylopoulos, 2006; Schatten, 2012a, 2012b, 2013; Schillo, Fischer, 2004; Schillo et al., 2004). Herein we will take a similar approach with one particular organizational form in mind - the learning organization (Senge, 1997), and especially the knowledge creating company (Nonaka, Takeuchi, 1995). As it will be shown, if smart residential buildings are considered as artificial learning organizations an elegant framework emerges that allows us to reason about complex solutions that might be implemented in such systems.

The rest of the article is organized as follows: firstly we provide a framework for defining smart residential buildings as multi-agent organizations. Afterwards we give an outline on the concept of the learning organizations with a special accent on ideas that might be applicable for the issue at hand. Then we provide an organizational agent model based on ideas from the learning organization. In the end we draw our conclusions and give guidelines for future research in this area.

\section{Smart Residential Buildings as Multi-agent Organizations}

In the following we will use the conceptualization of multi-agent organizations provided in (Schatten, 2012a, 2013). According to this view a multi-agent organization can be modelled across five dimensions which correspond to the paradigm of organizational architecture (CTI, 2004; Churchill, 1997; Galbraith, 1995; Henning, 1997; Merron, 1995; Nadler, Gerstein, Shaw, 1992; Nadler, Tushman, 1997): (1) organizational structure, (2) processes, (3) organizational culture, (4) strategy and (5) individual agents. Herein we will especially concentrate on organizational 
structure and organizational culture since they are the main building blocks of the learning organization as shall be shown further.

Individual agents from our perspective are described by their internal knowledge base and a number of behaviours which might be role factory (behaviour added at runtime and then enacted by the agent), itinerary (behaviour which allows mobile agents to travel across various locations and perform tasks), periodic (a behaviour which is looped possibly with a given period of time intervals between iterations), observer (behaviour in which an agents awaits an event in order to perform its actions), listener (a special type of observer behaviour in which and agent awaits a message of some other agent, client/server (behaviour which resembles the clientserver model, e.g. the client sends requests, the server responds to them), task or one-shot behaviour (a behaviour which represents a simple task or activity which is stopped after performance), finite state machine (a behaviour which resembles a finite state machine in which every node is an activity to be performed), sequential behaviour (a sequence of other behaviours) and parallel (various behaviours are run in parallel) (Marian et al., 2004).

We will assume a very simple smart resident building that consists of a number of floors which host a number of apartments and a number of smart devices which are mutually interconnected and installed across the building (in floors, halls, elevators, apartments or even mobile). Such a configuration can easily be extended with other architectural elements but for the sake of this conceptualization this configuration shall be enough.

The organizational structure of our smart resident building might be easily hierarchical organized. Organizational units on various level of detail can represent the building as the whole organization $\left(o^{S M R}\right)$, floors $\left(o_{i}^{F}, i \in F L\right.$, where $F L$ is a set of floor labels), individual apartments or flats $\left(o_{j}^{a}, j \in A L\right.$, where $A L$ is a set of apartment labels), rooms inside apartments of other facilities $\left(o_{k}^{r}, k \in R L\right.$, where $R L$ is a set of room labels), individual "things" or agents $\left(a_{l}, l \in A\right.$, where $A$ is the set of all agents). We additionally define the set of all organizational units $O$. Due to the recursive definition of organizational units (organizational units consist of organizational units at a lower level) we are now able to observe this agent organization on various levels of detail similarly to other aggregation approaches like holonic (Fischer, Schillo, Siekmann, 2003), aggregate (Lamarche-Perrin, Demazeau, Vincent, 2013), swarm-based (Terna, 2002), andmulti-level (Gil-Quijano, Louail, Hutzler, 2012) MAS.

Organizational culture represents the intangible aspects of an organization, and most prominently knowledge which is stored in form of organizational memory. The holders of knowledge can be agents ("things") or the environment (especially humans which use the MAS organization). In our case organizational knowledge is embedded into agents' knowledge bases, on-line services and residents. Thus, we have three sets of knowledge artefacts: $K^{A}=\left\{k_{1}^{A}, \ldots, k_{n}^{A}\right\}$ - set of agent knowledge artefacts (configuration, protocols, stored data etc.), $K^{O}=\left\{k_{1}^{O}, \ldots, k_{m}^{O}\right\}$ - set of knowledge artefacts provided by on-line services (Web and RESTful services, on-line databases etc.), and $K^{R}=\left\{k_{1}^{R}, \ldots, k_{o}^{R}\right\}$ - set of residents' knowledge artefacts (a wide range of human knowledge about them and the world). 


\section{The Learning Organization}

A simple definition of a learning organization is that it is an organization which employees continuously learns new skills which they apply in increasing the quality of the products and services the organization provides (Noe, 1986). It is a place where humans steadily widen their potentials to achieve better results, where new models of thought are developed, and where people learn how to learn together (Senge, 2006, p. 14). It is an organizational form which repeating widens its capacity in order to achieve its objectives (Bahtijarević-Šiber, 1999. p. 770).

Jennings (2000) provides a number of guidelines for achieving and maintaining a learning organization:

- Business policy and management structures have to allow for change which is the result of individual action. That subsumes that individuals are empowered to ask questions, publicly deliberate about them as well as have an influence on organizational events especially those which concern them;

- The organization has to have the will and desire to seek and notice feedback from its environment by asking questions to people and organizations it makes business with. It has to be mentioned that not only individuals can change the organization, but also the organization can change its environment by seeking information from it and about it;

- Individuals must have the right to be flexible in what and how they do;

- Individuals must be allowed to think about phenomena they encounter by themselves, in order to make own conclusions, rather than that they are taught what they should think. Discussions and divergence in thought are always possible. Such conflicts have to be tolerated and resolved constructively in order to learn from them;

- It has to be understood that the individual with its unique knowledge is the most valuable asset of the organization that has to be put to good use;

- Everyone in the organization has to learn, not only the management;

- Is has to be understood that the development of a learning organization is an ongoing process, not a one-time event.

Organizational learning to be adopted by organizations should be:

Cyclic learning. Once acquired knowledge is enriched by new information through a continuous cycle of learning.

Learning by doing. An organization and its individual employees learn by performing their work. Without the right action there will be no right answers or learning from errors. By deciding about action and monitoring its impact new information is acquired and learned (Self Renewal Group, 2000). Learning is becoming an integral part of the work process, meaning that the difference between doing and learning disappears (Bahtijarević-Šiber, 1999. p. 771)."

Collective learning. Everybody learns by doing, and in a way we are continuously "going to school". Learning is happening all the time (Robbins, 1993). Nevertheless, it is necessary to educate and train employees in methods and techniques which are needed to change the work process in order to find new solutions. Such techniques might include new marketing, organization, IT or planning techniques which are not necessarily part of an employee's everyday work. Thus training teams should be established in order for employees to learn skills from others in their organizational unit and understand the mutual correspondence between their own work and activities of the organizational unit as a whole (Bahtijarević-Šiber, 1999. p. 771). 
Context-aware learning. To be aware means to know what is being perceived in the moment it is perceived: the perception of a thing or situation, the content of out thought, a sentiment or desire (Petz, 1992, p. 440). In business organizations context-aware learning deals particularly with planned learning activities like trainings, seminars and life-long learning; but also with the awareness of employees when, where and how they perceive something new and memorize it.

Multi-directional learning. Such learning occurs when there is a large enough discrepancy between individual thoughts which then motivate argumentation (Self Renewal Group, 2000).

Additional insights into the processes behind learning and knowledge creation can be found in the notion of the knowledge creating company as described by Nonaka and Takeuchi (1995). They based their conceptualization on the knowledge spiral shown on figure 1 (Barlow, 2000). The spiral of knowledge consists of four processes which are bound to two types of knowledge implicit (hidden, latent, delitescent) and explicit (evident, external, and written):

Socialization. The first process, socialization, is the transposition of implicit knowledge again into implicit knowledge. This is achieved by observing foreign behaviour and adopting it. Humans, for example, learn how to speak and survive in their community solely by this process.

Externalization. The second process, externalization, is the process of transforming implicit into explicit knowledge. It is achieved by formalizing ("writing down") internal knowledge to be observable by others. For example, a skilled programmer might write down his experience in good programming techniques.

Internalization. Internalization represents the transformation of explicit into implicit knowledge. It is the process in which something we learned becomes an automated behaviour. For example, when a person learns how to drive, it thinks about all the manual steps fully aware (when to brake, when to look at the mirrors, when to change the gear etc.). Once learned, the person becomes unaware of its actions; the actions become an automated process.

Combination. In the combination process, explicit is again transformed into explicit knowledge. It is achieved by combining explicit knowledge into new findings. Most academic institutions rely mostly on this process.

Nonaka further explains that, even if managers often think that knowledge is created exclusively in the combination process, it is much more effective and creative to create knowledge by going through all four quadrants. In this way various creative processes like group based problem solving, new product or service design and project management can have better outcomes. For some projects, it will be necessary to visit all quadrants multiple times, which is how a knowledge spiral emerges (Barlow, 2000).

According to Nonaka, combination and internalization are better adjusted to bureaucratic organizations, while socialization and externalization apply preferably to team based structures. This is summarized in the idea of the hypertext organization in which employees should (as do hyperlinks on WebPages) delineate bureaucracy and connects team based projects with hierarchical organized units (Barlow, 2000; Žugaj \& Schatten, 2008). Thus his organizational model consists of three layers:

Business system layer - represents the performance of day-to-day business processes in the organization. Since a hierarchical organized bureaucracy is most efficient for routine activities, this layer has a pyramidal structure. 
Project team layer - represents cross-functional, cross-divisional, and cross-process activities which enrich the knowledge of the organization. This layer has a team based network structure.

Knowledge based layer - represents a fictional layer in which the knowledge created in the previous two layers is re-categorized and put into new contexts. It represents the culture, the vision and the data and knowledge-bases of the organization.

Figure 1

The Spiral of Knowledge according to Nonaka

\section{Dialog}

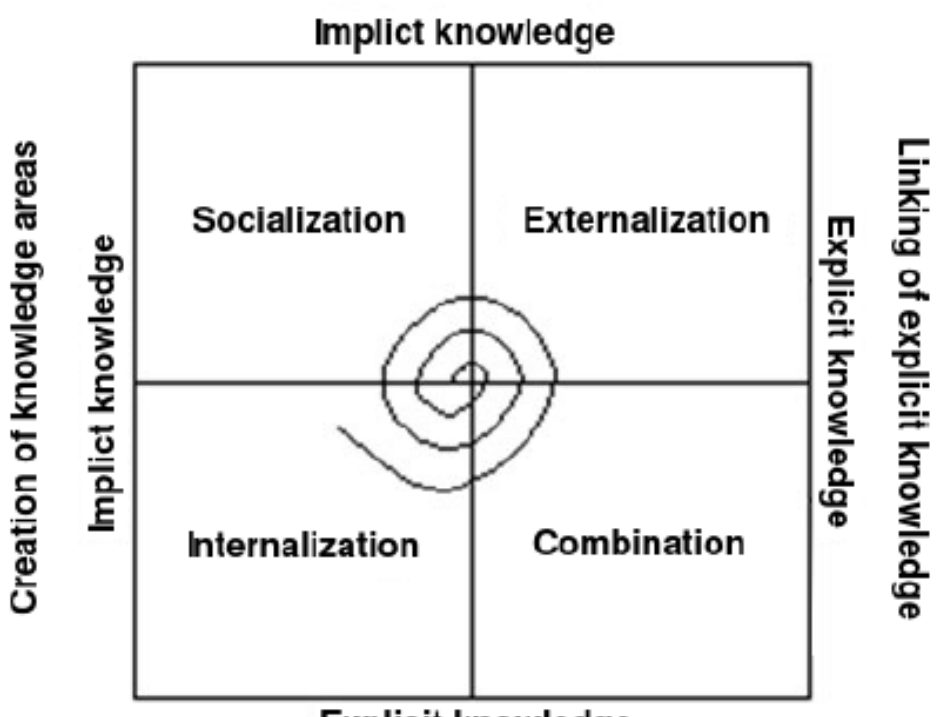

Explicit knowledge

Learning by dialog

Source: Nonaka, 2004

One of the most important characteristics of the hypertext organization is that employees are able to switch their context in order to foster adaptability, robustness and better reaction to influences from the environment. Knowledge is transferred between the layers and in continuously transformed into new and relevant knowledge for the organization (Rado, 2002). The model of the hypertext organization is presented on Figure 2.

\section{Organizational Agent Model}

Having discussed the learning organization in human corporations, we can now formalize this knowledge on our original agent organization model. From the guidelines provided by (Jennings, 2000) we might develop general principles for learning agent organizations:

1. (All) agents should be able to learn by observing and interacting with their environment.

2. Individual agents can have different opinions which might contradict due to the complex socio-technical system they are part of and interact with. 
3. The agent organization (not only individual agents) have to be context aware and in constant interaction with their environment.

4. The agent organization has to be aware of the individual knowledge its agents posses.

5. Agents have to be autonomous and flexible in action choice.

6. Agents have to be empowered to continuously change the system's organization.

Figure 2

Nonaka's Hypertext Organization

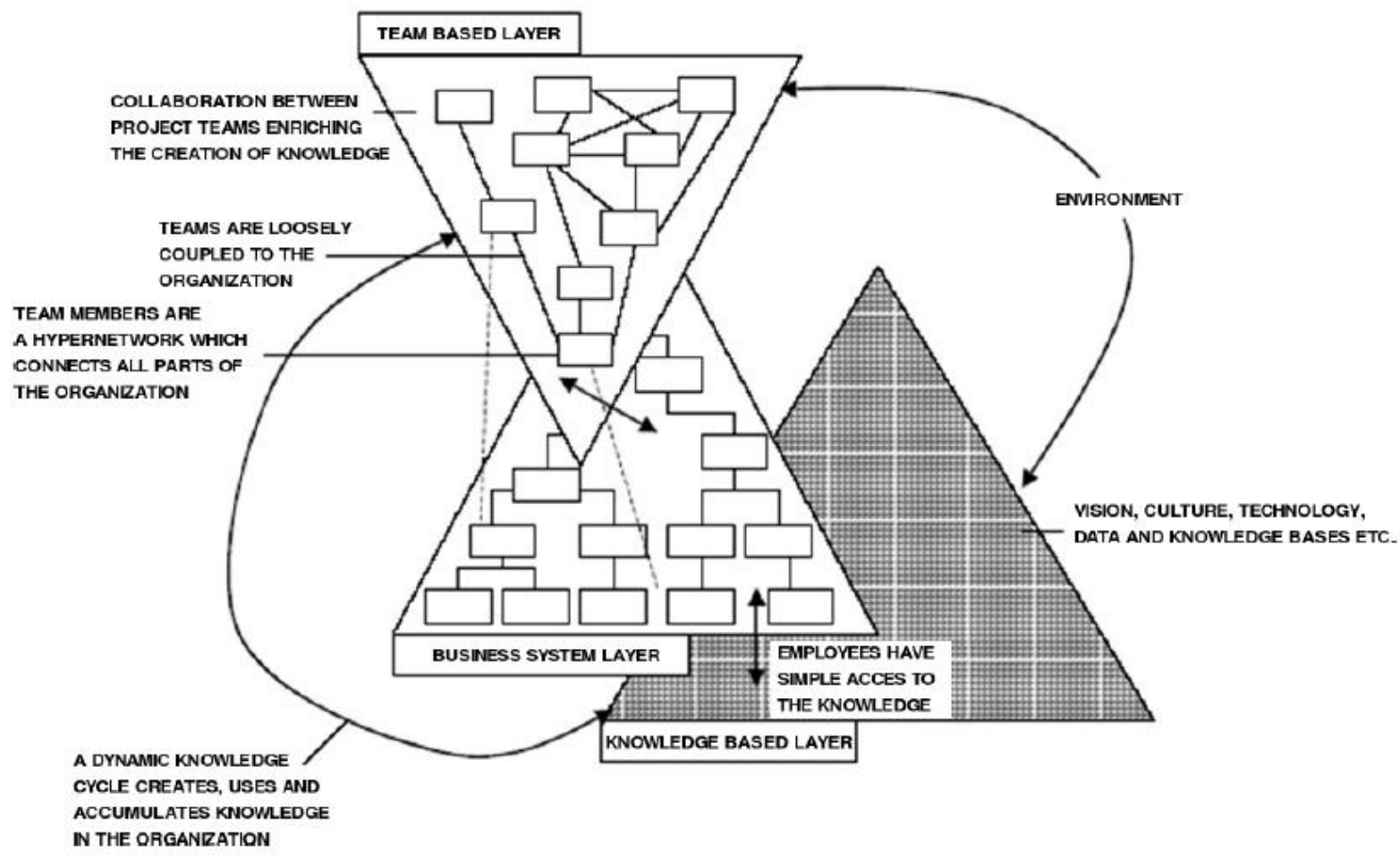

Source: Garavelli, 2004

These outlined principles can have major implications for both theory and practice. While principle 1 might sound trivial, giving the possibility to learn to all agents subsumes the need for developing learning algorithms for a very diverse range of sensor and actuator devices, as well as their implementation in embedded systems.

Principle 2 is bound to the previous, since by learning from a complex sociotechnical system, agents might reflect states of this often self-contradictory system (Schatten, Bača, Ivanković, 2009; Schatten, Maleković, Rabuzin, 2009). If an agent's knowledge becomes inconsistent with the knowledge of other agents, they might end up with conflicting views on cooperative behaviour. This implies the need for detection such inconsistencies as well as straightening them out.

In principle 3 the notion of context is not only bound to individual agents, but agent organizations. From a theoretical perspective, how does a group of agent become aware of anything? A possible solution might be to define context in form of metadata descriptors which assign important information about context (time, space, history of preceding events etc.) to individual knowledge artefacts. Such 
context descriptors could then be exchanged between agents. Thus for practice, protocols of context exchange have to be established.

Principle 4 provides another peculiar condition: agents have to be able to share their knowledge bases to other agents. In heterogeneous agent environments this might be a special challenge for practice.

Similarly, principle 5 could also be a challenge for development: how do we develop agents that might choose actions to perform depending on their own internal knowledge which might be inconsistent (remember principle 2). How do we ensure that such agent performance conforms to the needs and wants of residents?

Principle 6 from a practical viewpoint lets us ask the question: how do we engineer (complex) systems that can change their internal organization to avoid undesired (or even faulty) states and dynamics? From a theoretic perspective, how do we understand, model, implement and optimize organizational change for artificial organizations?

The various types of learning introduce the necessity of agents to perform various learning behaviours. Cyclic learning means that each agent has to have a periodic behaviour in which it continuously updates its knowledge base with information perceived from the environment. This is particularly true for various agents that adapt to human behaviour especially regarding providing ambient services tailored towards the needs of a resident (heating, humidity, luminosity, ambient music etc.). A number of machine learning techniques can be employed here to get selfoptimizing behaviour over time.

Learning by doing, on the other hand, implies the need for a mechanism in agents that will allow them to learn by observing the actions of it, the resident and other agents. Such behaviour might be modelled in form of an observer behaviour, which waits for actions to take place (the events) and then adds additional rules and facts to the knowledge base based on this observation. For example when a new agent ("thing") is introduced into an apartment or other facility, it might learn from other agents in range how to behave by observing their actions. A new speaker might in this way adjust its volume by observing the volume level of the other (already installed) speakers or configure its rules of functioning based on the already established rules in other speakers. Such an introduction of new behaviour could be modelled by a role factory. The observation of actions might be implemented in form of a complex event processor (WU, Diao, Rizvi, 2006) or active graph grammar (Schatten, 2012a, 2013), while the learning process could be developed by a method called implicit cultural learning (Birukou, Blanzieri, Giorgini, 2006; Blanzieri et al., 2001a, 2001b, 2004; Okreša Đurić, Schatten, 2012).

Collective learning states that not only those agents have to learn from each other, but that this process has to be organized. Thus agents have to be organized in organizational units (teams) which deal with particular types of knowledge artefacts. To reflect this necessity we will introduce a new type of organizational unit - learning teams $\left(o_{i}^{T}, i \in K^{A} \cup K^{O} \cup K^{R}\right)$ which is an overlay structure in the sense of virtual organizations as defined by (Barnatt, 1995). These organizational units are not part of the organizational hierarchy, but connect their parts (agents) in cross-unit teams. This technique might be especially useful in cases when new agents are introduced into the system. When the first agent that senses the presence of a new device, if the device of course is compatible and/or of a similar type, it might inform other devices of the team about it and its capabilities. The new agent might be added to the team and learn from the other agents as describe above.

Context-aware learning introduces two mechanisms: (1) the ability of individual agents to store not only knowledge artefacts, but their context of acquiring as well; 
and (2) a periodic behaviour which continuously checks for new and relevant knowledge artefacts from available on-line services. This is very similar to a well known feature: automated software updates. But, this behaviour does not have to be limited to such updates, for example a heating system might continuously observe weather forecast services and adjust its behaviour according to it.

Multi-directional learning takes into consideration that residents might not always behave rationally and thus introduce discrepancies into the learned knowledge of different agents. As an example, some resident might change her/his preferences over lighting intensity. Let us assume that the resident only uses two rooms in the period when the change in preferences has taken place. In this situation the lighting agents in these rooms will learn the new preferences, but other lighting agents are not aware of this change. Thus a discrepancy in beliefs between the individual agents emerges which has to be straighten out. One approach to this might be logical argumentation (Chesnevar, Maguitman, Lovi, 2000). The two agents might argue that the knowledge artefacts' they have acquired is newer than those of the other agents (this metadata has to be stored of course in a context descriptor).

The four processes of knowledge transformation describe agents' behaviours towards knowledge artefacts. For example, the process of socialization is bound to the learning by doing as described above. Agents observe the behaviour of other agents (which is the reflection of their internal knowledge artefacts) and make this artefacts part of their own knowledge base. The process of externalization gives agents the possibility to provide their own internal knowledge artefacts in form of services to other agents. In this way other agents can query the knowledge base of other agents which decided to provide such a service. On the other hand, the process of internalization allows agents to internalize knowledge artefacts from external (explicit) sources like various on-line services or querying services provided by other agents. This of course might induce additional behaviour for the agent possible instanced by a role factory behaviour. In the end, the process of combination makes it possible for agents to combine various sources of knowledge artefacts and provide them as a new amalgamated service (mash up applications being a very good example of this process).

The hypertext organization model integrates the above findings into a coherent structure. The business system layer represents the hierarchical organized agent structure (OSMR) which was already described. The team based layer is represented in form of learning teams of agents $\left(\mathrm{O}^{\top}\right)$ while performing a collective learning process. The Knowledge based layer is then the knowledge artefact infrastructure made up from various on-line and agent provided services.

\section{Conclusion \& Future Research}

In this paper we described smart resident buildings by borrowing ideas from organization theory, and especially the notion of a learning organization. It has been shown that there is much to learn from this particular organizational form that could enrich the theory and development of smart Internet of things devices for a class of application areas in which smart collaborating embedded devices have to learn from and adjust to a complex socio-technical system. Major challenges for both theory and practice have been outlined in form of six principles and a number of promising solutions have been proposed.

Various agent learning processes have been modelled using a number of agent behaviours as well as other advanced computational techniques. Examples of real world scenarios in which these types of learning might be of good use and methods for implementing them have been proposed as well. 
A framework for knowledge artefact sharing based on the knowledge spiral by Nonaka was introduced in form of knowledge artefact transformation processes and accompanying querying services. The learning and knowledge transformation processes have been integrated into an organizational structure that was modelled after Nonaka's hypertext organization. Our future effort is oriented towards building an integral agent development framework based in organization theory which shall include the formalization of organizational design methods which are applicable to multi-agent systems.

\section{References}

1. Argente, E., Julian, V., Botti, V. (2006), "Multi-agent system development based on organizations", Electronic Notes in Theoretical Computer Science, Vol. 150, No. 3, pp. 55-71.

2. Atzori, L., lera, A., Morabito, G. (2010), "The internet of things: a survey", Computer Networks: The International Journal of Computer and Telecommunications Networking, Vol. 54, No. 15, pp. 2787-2805.

3. Bahtijarević-Šiber, F. (1999). "Management ljudskih potencijala", Zagreb: Golden marketing.

4. Barlow, C. M. (2000), "The knowledge creating cycle", available at: http://www.cocreativity.com/handouts/nonaka.pdf (4 February 2004).

5. Barnatt, C. (1995), "Office space, cyberspace \& virtual organization", Journal of General Management, Vol. 20, No. 4, pp. 78-91.

6. Birukou, A., Blanzieri, E., Giorgini, P. (2006), "Implicit culture as a tool for social navigation", available at: http://eprints.biblio.unitn.it/archive/00000978/ (1 April 2012).

7. Blanzieri, E. et al. (2001a), "Implicit culture for multi-agent interaction support", Lecture Notes in Computer Science, Springer, Heidelberg Berlin, Vol. 2172, pp. 2739.

8. Blanzieri, E. et al. (2001b), "Information access in implicit culture framework", in Paques, H., Liu, L., Grossman, D. (Eds.), Proceedings of the tenth international conference on information and knowledge management CIKM '01, ACM: New York, pp. 565-567.

9. Blanzieri, E. et al. (2004), "Implicit culture-based personal agents for knowledge management", Agent-Mediated Knowledge Management, Lecture Notes in Computer Science, Springer, Heidelberg Berlin, Vol. 2926, pp. 245-261.

10. Bui, N., Zorzi, M. (2011), "Health care applications: a solution based on the internet of things", in Fratassi, S., Marchetti, N. (Eds.), Proceedings of the 4th international symposium on applied sciences in biomedical and communication technologies, ACM: New York, Article no. 131.

11. Chesnevar, C. I., Maguitman, A. G., Loui, R. P. (2000), "Logical models of argument", ACM Computing Surveys, Vol. 32, No. 4, pp. 337-383.

12. Churchill, C. (1997). "Managing growth: the organizational architecture of microfinance institutions", Bethesda: Development Alternatives.

13. CTI (2004), "Can your organization survive a tsunamie", available at: http://www.ctiarch.com/oa/optassess 1.htm (1 February 2004).

14. Desai, N., Chopra, A. K., Singh, M. P. (2009), "Amoeba: a methodology for modeling and evolving cross-organizational business processes", ACM Transactions on Software Engineering and Methodology, Vol. 19, No. 2, Article No. 6.

15. Dohr, A. et al. (2010), "The internet of things for ambient assisted living", in Latifi, S. (Ed.), Seventh International Conference on Information Technology: New 
Generations, 12-14 April, 2010, Las Vegas, USA, IEEE, Piscataway, pp. 804-809.

16. Ferber, J., Gutknecht, O., Michel, F. (2004) "From agents to organizations: an organizational view of multi-agent systems", in Giorgini, P., Müller, J. P., Odell J. (Eds.), Agent-oriented software engineering IV, Springer, Berlin Heidelberg, pp. 214-230.

17. Filipe, J. (2004), "Information fields in organization modeling using an EDA multiagent architecture", in Elst, L., Dignum, V., Abecker, A. (Eds.) Lecture Notes in Computer Science, Springer, Heidelberg Berlin, Vol. 2926, pp. 130-142.

18. Filipe, J., Fred, A. L. N. (2007), "Collective agents and collective intentionality using the EDA model", in Gelbukh, A., Morales, A. F. K. (Eds.), Sixth Mexican International Conference on Artificial intelligence - special session, IEEE, Piscataway, pp. 211-220.

19. Fischer, K., Schillo, M., Siekmann, J. (2003), "Holonic multiagent systems: a foundation for the organisation of multiagent systems", in Marik, V., McFarlane, D., Valckenaers, P. (Eds.), Lecture Notes in Computer Science, Springer, Heidelberg Berlin, Vol. 2744, pp. 71-80.

20. Galbraith, J. R. (1995). "Designing organizations: an executive briefing on strategy, structure, and process", San Francisco: Jossey-Bass Publishers.

21. Garavelli, C. (2004), "KM organisation, common approaches in KM", avalable at: http://www.knowledgeboard.com/library/deliverables/ekmfd21 cv082002\%20021 2iat.pdf (3 March 2004).

22. Garcia, E., Argente, E., Giret, A. (2008), "Issues for organizational multiagent systems development", in Jung B. et al. (Eds.), Sixth international workshop from agent theory to agent implementation, Estoril, Portugal, pp. 59-65.

23. Gil-Quijano, J., Lovail, T., Hutzler, G. (2012), "From biological to urban cells: lessons from three multilevel agent-based models", in Desai, N., Liu, A., Winikoff, M. (Eds.) Principles and practice of multi-agent systems, Lecture Notes in Computer Science, Springer, Heidelberg Berlin, Vol. 7057, pp. 620-635.

24. Henning, J. P. (1997). "The future of staff groups: daring to distribute power and capacity", San Francisco: Berrett-Koehler Store.

25. Horling, B., Lesser, V. (2005), "A Survey of Multi-Agent Organizational Paradigms", The Knowledge Engineering Review, Vol. 19, No. 4, pp. 281-316.

26. Hu, Z. et al. (201 1), "Iterative Model-based Identification of Building Components and Appliances by Means of Sensor-Actuator Networks", in Segovia, R., Zarli, A., Fies, B. (Eds.), Proceedings of the 2nd Workshop organised by the EEB Data Models Community "EEBuilding Data Models", 26-28 October 2011, Sophia Antipolis, France, Publications Office of the European Union: Luxembourg, pp. 216-226.

27. Jennings, D. (2000), "Learning climate and the learning organisation", available at: http://cis.paisley.ac.uk/wil-ci0/Jenlrn.htm (1 1 February 2000).

28. Kolp, M., Giorgini, P., Mylopoulos, J. (2006), "Multi-agent architectures as organizational structures", Autonomous Agents and Multi-Agent Systems, Vol. 13, No. 1, pp. 3-25.

29. Lamarche-Perrin, R., Demazeau, Y., Vincent, J. M. (2013), "How to build the best macroscopic description of your multi-agent system?", in Demazeau, Y. et al. (Eds.), Advances on Practical Applications of Agents and Multi-Agent Systems, Lecture Notes in Computer Science, Springer, Heidelberg Berlin, Vol. 7879, pp. 157-169.

30. Marian, T. et al. (2004), "A framework of reusable structures for mobile agent development", in Proceedings of IEEE international conference on intelligent engineering systems, IEEE, Piscataway, pp. 279-284. 
31. Merron, K. (1995). "Riding the wave: designing your organization's architecture for enduring success", New York: Van Nostrand Reinhold.

32. Nadler, D. A., Gerstein, M. S., Shaw, R. B. (1992). "Organizational architecture, designs for changing organizations", San Francisco: Jossey-Bass.

33. Nadler, D., Tushman, M. (1997). "Competing by design: the power of organizational architecture", Oxford: Oxford University Press.

34. Noe, R. A. (1986), "Trainees' attributes and attitudes: neglected influences on training effectiveness", Academy of management review, Vol. 11, No. 4, pp. 736749.

35. Nonaka, I. (2004). "Organizational knowledge creation", available at: http://www.Knowledge-

nurture.com/web/bulabdoc.nsf/0/86b566634bc84ea28625662c005c1996/\$FILE/n onaka.PDF (13 February 2004).

36. Nonaka, I., Takeuchi, H. (1995). "The knowledge-creating company, how japanese com panies create the dynamics of innovation", Oxford: Oxford University Press.

37. Okreša Đurić, B., Schatten, M. (2012), "Modeling multiagent knowledge systems based on implicit culture", in Hunjak, T., Lovrenčić, S., Tomičić, I. (Eds.), Central European conference on information and intelligent systems, Faculty of Organization and Informatics, Varaždin, pp. 57-61.

38. Pejić Bach, M., Stepanić, J., Strugar, I. (2012), "Embedded Systems Development Practices: Croatian Perspective", in Merkač Skok, M., Cingula, M. (Eds.), Proceedings of 4th International Scientific Conference „Knowledge and Business Challenge of Globalisation in 2012", Fakulteta za komercialne in poslovne vede, Celje, Slovenia, pp. 596-603.

39. Petz, B. (Ed.) (1992). "Psihologijski rječnik", Zagreb: Prosvjeta.

40. Rado, D. (2002), "Führung und organisation", available at: http://www.mavericks.ch/3download/files/unisg/unisgsumFuOws0102v10.pdf (14 February 2004).

41. Robbins, S. P. (1993), "Organizational behaviour: concepts controversies and applications", $6^{\text {th }}$ ed., New Jersey: Prentice Hall.

42. Schatten, M. (2012a), "Active graph rewriting rules for modeling multi-agent organizational dynamics", in Ivković, M., Pejić Bach, M., Šimičević, V. (Eds.), Proceedings of the IBC 2012, 1st International Internet \& Business conference, Rovinj, BIT Society, pp. 180-185.

43. Schatten, M. (2012b), "Complex analytical method for self-organizing multiagent systems", in Hunjak, T., Lovrenčić, S., Tomičić I. (Eds.), Central european conference on information and intelligent systems, Faculty of Organization and Informatics, Varaždin, pp. 49-55.

44. Schatten, M. (2013), "Reorganization in multi-agent architectures: an active graph grammar approach", Business Systems Research, Vol. 4, No. 1, pp. 14-20.

45. Schatten, M., Bača, M., Ivanković, M. (2009), "Public interfaces as the result of social systems structural coupling", in Mertik, M., Damij, N. (Eds.), Proceedings of the 1st international conference on information society and information technologies ISIT 2009, Dolenjske Toplice, Slovenia, Faculty of information studies in Novo mesto, pp. 6.

46. Schatten, M., Maleković, M., Rabuzin, K. (2009), "Inconsistencies in semantic social web applications", in Aurer, B., Bača, M., Rabuzin, K. (Eds.), 44. Central european conference on information and intelligent systems, Varaždin, Faculty of Organization and Informatics, pp. 3-6. 
47. Schillo, M. et al. (2004), "Form-a sociologically founded framework for designing self-organization of multiagent systems", in Lindemann, G., Moldt, D., Paolucci, M. (Eds.), Regulated agent-based social systems, Springer, Heidelberg Berlin, Vol. 2934, pp. 156-175.

48. Schillo, M., Fischer, K. (2004), "A taxonomy of autonomy in multiagent organisation", in Nickles, M., Rovatsos, M., Weiß, G. (Eds.), Agents and computational autonomy, Springer, Heidelberg Berlin, Vol. 2969, pp. 68-82.

49. Self Renewal Group (2000). "The learning organization", available at: http://www.srg.co.uk/learnorg.html (16 February 2000).

50. Senge, P. M. (1997), "The fifth discipline", Measuring Business Excellence, Vol. 1, No. 3, pp. 46-51.

51. Senge, P. M. (2006). "The fifth discipline: the art \& practice of the learning organization", $2^{\text {nd }}$ ed., New York: Crown Publishing Group.

52. Terna, P. (2002), "JVEFrame: a virtual enterprise frame in Swarm", in Swarmfest 2002 conference, available at: http://eco83.econ.unito.it/swarm/materiale/jve/jve.pdf (27 September 2012).

53. Vermesan, O. et al. (2011), "Internet of things strategic research roadmap", in Vermesan, O., Friess, P. (Eds.), Internet of Things: Global Technological and Societal Trends, River Publisher, Aalborg, pp. 9-52.

54. Vlacheas, P. et al. (2013), "Enabling smart cities through a cognitive management framework for the internet of things", IEEE Communications Magazine, Vol. 51, No. 6, pp. 102-111.

55. Welbourne, E. et al. (2009), "Building the internet of things using rfid: the rfid ecosystem experience", Internet computing, Vol. 13, No. 3, pp. 48-55.

56. Wooldridge, M. (2009). "An introduction to multiagent systems", $2^{\text {nd }}$ ed., Chichester: John Wiley \& Sons.

57. Wu, E., Diao, Y., Rizvi, S. (2006), "High-performance complex event processing over streams", in Yu, C., Schevermann, P., (Eds.), Proceedings of the 2006 ACM SIGMOD International Conference on Management of Data, ACM, New York, pp. 407-418.

58. Yun, M., Yuxin, B. (2010). "Research on the architecture and key technology of internet of things (IOT) applied on smart grid", in Tian, X. (Ed.), International Conference on Advances in Energy Engineering (ICAEE), 19-20 June 2010, Beijing, China, Institute of Electrical and Electronics Engineers: Piscataway, pp. 69-72.

59. Žugaj, M., Schatten, M. (2008), "Informacijski sustav za upravljanje znanjem u hipertekst organizaciji", Ekonomski vjesnik, Vol. 21, No. 1-2, pp. 19-30.

\section{About the author}

Markus Schatten is an assistant professor and the head of the Artificial Intelligence Laboratory at the Faculty of Organization and'Informatics, University of Zagreb. He is holding courses in Knowledge management, Programming, Database theory, Database management systems, Logic programming and Multiagent systems. He holds a PhD in information and communication sciences, MSc in information sciences and BSC in information systems. He authored and co-authored more than 60 scientific and professional papers under which a monograph book on modern organizational architectures. His research interest includes multiagent systems, semantic Web, Internet of things, organization theory, autopoiesis, social network analysis, and Web mining. Author can be contacted at markus.schatten@foi.hr 